\title{
Pembinaan Keagamaan dalam Lingkungan Keluarga Pengasuh Anak Korban Perceraian
}

\author{
Mimi Delfia1, Syaflin Halim2, Rahmi3 \\ Program Pascasarjana Universitas Muhammadiyah Sumatera Barat \\ Universitas Muhammadiyah Sumatera Barat \\ Email: mimidel@gmail.com
}

\begin{abstract}
Children Divorce victims are faced with a variety of life problems that boil down to their future, this study aims to describe how the methods used as well as the material that the caregiver's family teaches to the child of the divorce victim in the family environment. This research was conducted with qualitative approach, data source consisting of parents of child caregivers divorce victims, children who are victims of divorce, public figures who are purposively selected. Data collection techniques are carried out by observation, interviews and documentation studies. The results prove that there are several methods used by the caregivers of divorce victims in teaching Islam in the family environment such as the method of nudity, the method of story of the total method of pysik response. Adapaun Islamic religious material taught to children of divorce victims in the family environment is related to faith, worship, and morals.
\end{abstract}

Keyword: child victim of divorce, Islamic Education, Method and Material

\begin{abstract}
Abstrak
Anak Korban perceraian dihadapkan berbagai problem kehidupan yang bermuara pada masa depannya, penelitian ini bertujuan untuk menggambarkan bagaimana metode yang digunakan serta materi yang diajarkan keluarga pengasuh terhadap anak korban perceraian di lingkungan keluarga. Penelitian ini dilakukan dengan pendekatan kualitatif, sumber data terdiri dari orang tua pengasuh anak korban perceraian, anak yang menjadi korban perceraian, tokoh masyarakat yang dipilih secara purposive. Teknik pengumpulan data dilakukan dengan observasi, wawancara dan studi dokumentasi. Hasil penelitian membuktikan bahwa ada beberapa metode yang digunakan oleh pengasuh anak korban perceraian dalam mengajarkan agama Islam di lingkungan keluarga seperti metode keteladanan, metode kisah metode total pysik respon. Adapaun materi agama Islam yang diajarkan kepada anak korban perceraian di lingkungan keluarga ialah terkait akidah, ibadah, dan akhlak.
\end{abstract}

Kata Kunci: Anak Korban Perceraian, Pendidikan Agama Islam, Metode dan Materi

\section{Pendahuluan}

Pendahuluan harus berisi (secara berurutan) (1) fenomena umum, (2) fenomena khusus atau yang berkaitan langsung dengan kondisi tempat pelaksanaan kegiatan KKL, (3) permasalahan yang dikaji, (4) dugaan yang menyebabkan dan faktor yang paling dominan/determinan, (15) mengapa penting untuk dilakukan kegiatan KKL di daerah tersebut. Masing-masing memiliki porsi sebagai berikut: 
Salah satu bentuk syariat Islam dalam kehidupan adalah membina rumah tangga yang sakinah mawaddah dan warahmah, di dalam menjalani kehidupan rumah tangga akan muncul hak dan kewajiban suami dan istri dan hak dan kewajiban antara orang tua dan anak. ${ }^{1}$ Seiring dengan berjalannya perkawinan, rumah tangga akan dihadapkan dengan berbagai konflik baik lahir maupun batin. ${ }^{2}$ Salah satu konflik lahir adalah kesulitan ekonomi, tidak layak/tidak ada tempat tinggal, atau kekurangan materi yang lain. ${ }^{3}$ Sementara konflik batin seperti terjadinya perselisihan antara suami isteri, kekerasan dalam rumah tangga atau masuknya pihak ketiga yang mengganggu keharmonisan rumah tangga. ${ }^{4}$

Puncak akhir sebuah konlik biasanya terjadinya perceraian orang tua, ${ }^{5}$ yang biasanya disebut dengan cerai hidup. Dan dari perceraian ini maka anak menjadi salah satu korban yang menanggung resikonya, ${ }^{6}$ namun ada juga yang disebut dengan cerai mati yaitu berpisahnya suami isteri karena meninggal salah satu pasangan. Dari kasus cerai hidup dan cerai mati ada ana yang tidak lagi diasuh oleh orang tuanya, namun diserahan kepada keluarga terdekat atau panti asuhan. $^{7}$

Dari kasus perceraian ini akan memunculkan permasalahan baru bagi anak, ${ }^{8}$ di antaranya ialah tidak semua ayah bertanggungjawab memberi nafkah ${ }^{9}$, antara anak dengan orang tua putus komunikasi, ibu menjadi tulang punggung

1 Tenda Budiyanto, "Membangun Komitmen Dalam Pernikahan Dan Keluarga," Tsamrah Al-Fikri 12, no. 2 (2018): 85-94.

2 P. Tyler Roskos, Paul J. Handal, and Megan E. Ubinger, "Family Conflict Resolution: Its Measurement and Relationship with Family Conflict and Psychological Adjustment," Psychology 1, no. 5 (2010): 370-76, https://doi.org/10.4236/psych.2010.15046.

${ }^{3}$ E Ndayambaje, Y Umwari, and Y. Ayriza, "The Impact of Family Conflicts on Children's Education.," International Journal of Pedagogy and Teacher Education 4, no. 2 (2020): 10518.

${ }^{4}$ Frank D Fincham and Steven R H Beach, "Conflict in Marriage: Implications for Working with Couples," Annu. Rev. Psychol. 50, no. February (1999): 47-77, https://doi.org/10.1146/annurev.psych.50.1.47.

${ }^{5}$ Harry Ferdinand Mone, "Dampak Perceraian Orang Tua Terhadap Perkembangan Psikososial Dan Prestasi Belajar," Harmoni Sosial: Jurnal Pendidikan IPS 6, no. 2 (2019): 155-63, https://doi.org/10.21831/hsjpi.v6i2.20873.

${ }^{6}$ Kartika Sari Dewi and Adriana Soekandar, "Kesejahteraan Anak Dan Remaja Pada

Keluarga Bercerai Di Indonesia: Reviu Naratif Kartika," Wacana 11, no. 1 (2019): 42-78, https://doi.org/10.13057/wacana.v11i1.135.

7 Luthfita Cahya Irani and Eko Pramudya Laksana, "Konsep Diri Dan Keterbukaan

Diri Remaja Broken Home Yang Diasuh Nenek," Jurnal Pendidikan: Teori, Penelitian, Dan Pengembangan 3, no. 5 (2018): 685-92.

8 Bambang, Mahyudin Ritonga, and Ahmad Lahmi, "The Role of Parents in Shaping Children's Behavior During the Covid-19 Pandemic," International Journal of Disaster Recovery and Business Continuity 11, no. 3 (2020): 3223-28.

9 Suparman et al., "The Implementation of Community Partnership Program to Improve the Quality of Online Learning during the Covid-19 Pandemic," Universal Journal of Educational Research 8, no. 11B (2020): 6134-38, https://doi.org/10.13189/ujer.2020.082249. 
keluarga, orang tua menikah lagi, anak ditinggal atau dititipkan pada keluarga terdekat.

Dari permasalahan di atas peran orang tua sebagai lembaga pertama yang mendidik anak-anaknya tidak berjalan dengan baik. Jika orang tua tetap memperhatikan anaknya walaupun sudah terjadi perceraian, mendidik sesuai dengan agama Islam dan ditambah dengan ilmu-ilmu dunia lainnya maka orang tua insya Allah akan mendapatkan anak-anak yang shaleh, berilmu dan mandiri. Namun jika orang tua tidak acuh dengan pendidikan agama anaknya maka kelak akan tercipta anak-anak yang menyusahkan, membebani orang tua, hidup tanpa tujuan bahkan menjadi anak yang durhaka.

Dalam penelitian metode yang penulis gunakan adalah kualitatif, sedangkan prosedur penelitian yaitu hasil data deskriptif artinya penelitian yang menggambarkan suatu kasus yang terjadi di lapangan sebagaimana adanya. Sebagaimana diungkapkan oleh Sutrisno Hadi yaitu metode kualitatif merupakan prosedur penelitian dengan hasil data deskriptif baik dalam bentuk kata-kata atau perbuatan, kata-kata lisan, kata-kata lisan seseorang atau perilaku manusia yang dapat diamati.

Data primer adalah data yang penulus peroleh langsung dari tempat penelitian. Data primer dalam penelitian ini adalah hasil wawancara dengan masyarakat Desa Pakasai Padusunan Kecamatan Pariaman Timur, khususnya orang-orang terdekat yang mengurus anak korban perceraian, para anak korban perceraian, dan Kepala Desa dan Tokoh masyarakat. Data sekunder adalah data yang diambil dari lapangan, berupa dokumen-dokumen tentang hal diteliti. Seperti data di Desa,: data masyarakat desa menurut tingkat pendidikan, ekonomi, propesi , foto kegiatan keagamaan dan sosial seperti Mengaji, Olah Raga, Wirid mingguan.

\section{Hasil dan Pembahasan}

Dari observasi penulis dilapangan pengenalan kalimat tauhid dimulai semenjak bayi baru dilahirkan yaitu melalui azan dan iqamah, adapun pengenalan selanjutnya dalam ucapan sehari-hari, sehingga anak menjadi terbiasa juga mengucapkan kata-kata tauhid tersebut.

Penulis menyimpulkan bahwa keluarga terdekat anak korban perceraian ada yang mengenalkan dan ada pula yang tidak mengenalkan kalimat tauhid, namun semua anak kecuali Yugo Ardi sudah aham dengan kalimat tauhid. Pada dasarnya anak-anak sudah memahami kalimat tauhid karena sering didengar dan diucapkkan, apakah itu dalam pembicaraan sehari-hari atau di lembaga pendidikan agama, sehingga tidak berat di lidah mereka untuk mengucapkan kalimat tauhid.

Bapak Syarizal selaku Kepala Desa mengungapkan, penanaman nilainilai pendidikan Islam dimulai semenjak anak dalam kandungan, kemudian lahir maka orang tua atau amili lainnya mengazankan atau mengiqamatkan. Kemuadian orang tua atau keluarga terdekat bertanggung jawab penuh dalam 
membentuk nilai-nilai ketauhidan anak, disamping menyerahkan anaknya untuk belajar di lembaga pendidikan seperti TK/PAUD, SD / MI, MDA, Pondok Qur'an atau lembaga pendidikan lainnya.Adapun bentuk pengelolaan yang diberikan pemerintah desa seperti menganggarkan dana desa untuk honor guru mengaji atau pondok al qur'an, perbaian sarana prasarana pondok Qur'an

Adapun metode yang diterapkan dalam pengenalan kalimat tauhid ini bagi Ibuk Nurmisyam adalah metode pembiasaan, Ibu Elvinawati metode keteladanan dan pembiasaan, Ibu Masni dengan reward yaitu menyanyikan sehingga anak tertidur, sementara ibu Kasmawali, Alianis, Nurbani hanya mengandalkan dari sekolah atau surau saja. Adapun Martina selalu memberikan pujian jika anak saudaranya tersebut berzikir setelah shalat.

Metode keteladanan sebagaimana yang dilakukan pengasuh adalah bagian dari metode pembelajaran yang telah banyak digunakan dalam pembelajaran di berbagai lembaga pendidikan, terutama dalam masalah yang terkait dengan materi yang bersifat praktis, ${ }^{10}$ memberikan keteladanan bagi peserta didik adalah hal yang utama disebabkan sikap dan kebiasaan anak yang suka untuk meniru setiap apa yang dilihatnya. ${ }^{11}$ Keluarga terdekat yang mengasuh anak korban perceraian di Pariaman Timur telah memberikan keteladanan baik dalam mendirikan shalat lima waktu maupun dalam kegiatan agama yang bersifat praktis di lingkungan keluarga.

Selain berupa keteladanan, keluarga terdekat yang mengasuh anak korban perseraian juga melakukan Tahnik dan Aqiqah. Menurut Observasi penulis di lapangan bahwa kegiatan taknik ini jarang dilakuan orang tua sewatu anaknya lahir, hanya orang-orang tertentu yang melakuan, hal ini karena tidak semua orang tahu dengan tahnik. Adapun Aqiqah semua keluarga terdekat yang penulis wawancarai mengetahui aqiqah, namun dalam pelaksanaannya aqiqah di lakukan tidak hanya waktu anak berusia 7 hari saja, ada yang usia 14 hari, 21 hari atau 1 tahun bahan ada yang menjelang akad nikah.

Dari hasil wawancara penulis menyimpulkan bahwa tidak ada seorangpun anak yang diasuh tadi yang dilakukan tahnik, begitu juga dengan aqiqah, hal ini dikarenakan keterbatasan ekonomi orang tuanya/keluarga terdekatnya. Namun jika diucapkan kata-kata aqiqah, anak-anak sudah paham dengan maksudnya.

Mengadakan tahnik dan aqiqah bagi anak secara hukum Islam menduduki posisi penting, hasil analisis beberapa pemikir terhadap aqiqah menyimpulkan bahwa mengandung nilai pendidikan yang sangat luas, di dalamnya mengajarkan kepada umat Islam agar terhindar dari sifat-sifat yang dimiliki oleh binatang, dan yang terpenting adalah pelaksanaan aqiqah

${ }^{10}$ Nurul Hidayat, "Metode Keteladanan Dalam Pendidikan Islam," Ta'allum: Jurnal Pendidikan Islam 03, no. 02 (2015): 135-50, https://doi.org/10.21274/taalum.2015.3.2.135-150.

11 Rosniati Hakim et al., "Implementation of Contextual Teaching and Learning in Islamic Education at Madrasah Diniyah," Journal of Advanced Research in Dynamical \& Control Systems 12, no. 02 (2020): 3326-32, https://doi.org/10.5373/JARDCS/V12I2/S20201455. 
mengajarkan agar umat memiliki tauhid yang kuat sebagaimana layaknya Nabi Ibrahim sebagai tauladan dalam aqiqah, ${ }^{12}$ Al-Kasyairi dalam analisisnya juga mengungkapkan bahwa pelaksanaan ibadah aqiqah tidak terbatas pada ibadah ritual semata melainkan memiliki dan mengandung nilai pendidikan. ${ }^{13}$

Sesuai dengan data yang ditemukan serta kesimpulan para peneliti terdahulu diketahui bahwa pelakasanaan tahnik dan aqiqah bagi anak korban perceraian mengandung makna yang erat kaitannya dengan pendidikan Islam, melalui ibadah aqiqah diharapkan anak terhindar dari sifat-sifat buruk, melalui aqiqah juga anak mulai diajarkan untuk mencintai Allah lebih dari segalanya. Dengan demikian pola yang dilakukan keluarga pengasuh anak korban perceraian seperti yang ditemukan di Pariaman merupakan bukti keinginan mereka menjadikan anak tersebut memiliki pengalaman dan pengamalan agjaran Islam.

Langkah selanjutnya yang dilakukan oleh keluarga pengasuh anak korban perceraian ialah menanamkan kecintaan kepada Allah dan rasulnya. Pola ini dilakukan melalui 1) Memperkenalkan nama Allah dan rasulnya, hasil obsevasi penulis semua anak sudah mengenal Allah sebagai penciptanya, dan memahami hak dan kewajiban terhadap Allah. Hasil wawancara penulis menyimpulkan bahwa metode yang digunakan keluarga terdekat adalah metode kisah atau cerita, sementara itu Ibu Alianis, Nurbani, Kasmawati dan Mursyida jarang bercerita tentang Allah dan rasulnya. Alianis menjelaskan bahwa dia sangat suka untuk menceritakan hal-hal yang terkait dengan bukti kekuasaan Allah dan keutamaan Rasul sebelum tidur kepada anak yang diasuhnya.

Memperkenalkan Allah juga dilakukan oleh pengasuh dengan 2) Menggambarkan makhluk ciptaan Allah melalui visual atau cerita menarik. Menggambarkan tentang ciptaan Allah kepada anak merupakan suatu hal yang dapat membuat anak berfikir akan kebesaran Allah dan bersyukur, namun tidak semua keluarga terdekat mampu mengenalkan dan menceritakan kebesaran Allah yang akan meningkatkan ikatan anak kepada Allah, Dalam hal ini penulis hanya mendapatkan jawaban dari keluarga terdekat melalui cerita saja. Hasil observasi dan wawancara, penulis menyimpulkan bahwa untuk menggambarkan tentang penciptaan alam / makhluk kebanyakan melaui metode cerita, apakah itu di dapat anak di rumah atau melalui bangku sekolah.

Selanjutnya orang tua pengasuh juga 3) Mengajarkan anak membaca AlQur'an. Mengajarkan Al-Qur'an semenjak dini merupakan tanggung jawab orang tua atau keluarga terdekat, dari observasi penulis dilapangan semua anak yang penulis teliti kecuali Yugo Ardi sudah mampu membaca Al Qur'an dengan baik. Adapun metode yang digunakan bermacam-macam.

12 Nurul Azizah, "Nilai-Nilai Pendidikan Islam Dalam Hadis-Hadis Akikah," PROGRESS: Jurnal Pendidikan Agama Islam Universitas Wabid Hasyim 7, no. 1 (2019): 81-102.

${ }^{13}$ M Khoir Al-kusyairi, "Nilai-Nilai Pendidikan Dalam Hadits Ibadah Aqiqah," Jurnal $\begin{array}{lllll}\text { Al-Hikmah } & 12, & & \end{array}$ https://journal.uir.ac.id/index.php/alhikmah/article/view/1456.

Jurnal WARAQAT • Volume VI, No. 1, Januari - Juli 2021 | 5 
Hasil observasi dan wawancara penulis menyimpuklan bahwa metode keteladanan dan nasehat diterapkan oleh Ibuk Jamini dan Masni, semntara Ibu Nurmisyam, Alianis, Mursyida, mengunakan metode pembiasaan. Ibu Elvinawati dan Martina melalui pembiasaan dan reward,sementara Ibu Nurbani menggunakan metode pembiasaan dan nasehat. yaitu membiasakan anak untuk menuntuk ilmu al qur'an di surau atau MDA.

Adapun bentuk keterlibatan desa dalam pendidikan Al qur'an ini diantaranya menyediaan honor bagi guru mengaji, mengikut sertakan anak-anak untuk lomba MTQ, Hafiz qur'an baik tingkat kecamatan ataupun kabupaten.disamping itu masyarakat juga berperan serta untuk memberikan sumbangan tetap untuk kelanjutan program pondokk qur'an ungkap Bapak Syafrizal.

Ditambahkan lagi oleh Mujahidin selaku alim ulama bahwa dia sering mengikuti shalat berjamaah dengan anak-anak mengaji, dan memotivasi mereka untuk belajar lebih giat, salah satunya menceritakan seorang tokoh yang bernama Irdas Raja, sukses menjadi da'i, anggota DPRD, Dosen dan tokoh masyarakat karena belajar mengaji di surau, belajar adat di surau dan tekun belajar di sekolah sampai mendapatkan beasiswa dari berbagai instansi. Sebagai alim ulama Bapak mujahidin hanya bisa memberikan dorongan moral sementara tanggng jawab utama tentu tetap berada pada keluarga terdekat, ungkapnya.

Hasil penelitian sesuai dengan data yang dijelaskan di atas bila dikonversikan dengan beberapa temuan para peneliti terdahulu maka dapat diketahui bahwa mengajarkan anak tentang kecintaan kepada Allah adalah suatu langkah untuk menambah wawasan dan pengetahuan mereka tentang sang khalik, seseorang yang tidak mengenal Tuhan maka akan sulit untuk menjadikannya pribadi yang mematuhi aturan Tuhan. ${ }^{14}$ Keluarga Muslim bisa saja mengajarkan anak agar memiliki keimanan dengan memulainya dari lingkungan keluarga. ${ }^{15}$

Teknik atau metode yang digunakan keluarga pengasuh sebagaimana data yang didapatkan ialah melalui cerita kepada anak. Metode cerita adalah bagian dari metode pembelajaran yang lazim digunakan dalam pendidikan Islam, bahkan kisah-kisah umat terdahulu dapat diajarkan kepada anak melalui cerita, teknik bercerita dapat merangsang peserta didik untuk megetahui peristiwa dimasa lampau. ${ }^{16}$ Penggunaan metode yang baik adalah unsure utama dalam

14 Shofaussamawati, "Iman Dan Kehidupan Sosial," Riwayab: Jurnal Studi Hadis 2, no. 2 (2016): 211-24, journal.stainkudus.ac.id/index.php/Riwayah.

15 Azhar et al., "The Role of Parents in Forming Morality Adolescents Puberty in Globalization Era," International Journal of Future Generation Communication and Networking 13, no. 4 (2020): 3991-96.

16 Asyruni Multahada, "Keterampilan Menggunakan Metode Cerita Dalam Pembelajaran Pendidikan Agama Islam Di TPQ," Intizar 24, no. 2 (2018): 2019-2226, https://doi.org/10.19109/intizar.v24i2.2586. 
tercapainya tujuan yang diharapkan ${ }^{17}$. Keluarga pengasuh anak korban perceraian sebagaimana data penelitian juga mengajarkan anak agar membaca alQuran, mereka terkadang memasukkan anak agar aktip belajar mengaji di Masjid/Mushalla terdekat, belajar di rumah sendiri bahkan ada di antara mereka yang mengundang guru secara private untuk mengajarkan al-Quran kepada anak yang menjadi korban perceraian.

Pembelajaran baca tulis al-Quran bagi generasi muslim penting untuk dilakukan, ${ }^{18}$ hal ini terkait dengan posisi al-Quran yang berbahasa Arab membutuhkan pola pembelajaran yang berbeda dengan dengan materi-materi lain. Karena, secara psikologis jangankan untuk belajar bahasa yang bukan bahasa mereka mempelajari bahasa yang mereka sudah terbiasa saja sulit. ${ }^{19}$ Mempelajari al-Quran kewajiban masing-masing setiap orang Islam, tidak mungkin bisa memahami al-Quran kalau membacanya saja tidak bias, ${ }^{20}$ dan tidak akan mungkin seseorang bisa mengamalkan al-Quran kalau dia tidak bisa membacanya.

Sesuai dengan hasil penelitian, baik yang didapatkan melalui observasi, wawancara dan studi dokumentasi diketahui bahwa keluarga pengasuh anak korban perceraian memberikan materi pendidikan agama Islam bagi anak korban perceraian yang mereka asuh meliputi materi aqidah, ibadah dan akhlak. Namun secara umum mereka tidak mengajarkannya secara terstruktur maupun secara teratur dan berjenjang.

Hasil observasi penulis di lapangan menyimpulkan bahwa semua anak korban cerai lancar dalam gerakan dan bacaannya kecuali Yugo Ardi, hal ini disebabkan karena anak setiapJum'at disekolah selalu membaca bacaan shalat sebelum masuk kelas, dan di mushallah pada hari Kamis Khusus untuk belajar praktek Shalat. Meskipun Semua anak lancar dan mampu dalam shalat namun tidak semua anak melaksanakan dengan penuh, mereka yang menginjak dewasa ada yang meninggalkan shalat dengan sengaja. Hasil observasi dan wawancara penulis menyimpulkan bahwa metode yang diterapkan rata-rata adalah

${ }^{17}$ Nurlaili, Mahyudin Ritonga, and Mursal, "Muroja'ah Sebagai Metode Menghafal AlQur'an Studi Pada Rumah Tahfiz Yayasan Ar-Rahmah Nanggalo Padang," Menara Ilmu XIV, no. 02 (2020): 73-82.

18 Saddam Husein, Radiudin Alfian Sangadji, and Laganti Salayar, "Urgensi Mempelajari Al-Qur'an Hadist Terhadap Prestasi Belajar Peserta Didik Di MTs Nurul Ikhlas Kalapa Dua Seram Bagian Barat," Al-Iltizam 3, no. 1 (2018): 1-13.

19 Nur Alim, Mahyudin Ritonga, and Mafardi, "Korelasi Kegiatan Ekstrakurikuler Sanggar Al-Quran Dengan Hasil Belajar Al-Quran Hadits Di MAN 4 Pasaman Barat," Intiqa: Jurnal Agama Dan Pendidikan Islam 12, no. 2 (2020): 246-55, https://doi.org/10.30596/intiqad.v12i2.4640.

${ }^{20}$ Reni Fauziah, Mahyudin Ritonga, and Fitri Alrasi, "Korelasi Tsiqah Tahfidz AlQur'an Dengan Maharah Al-Lughah Al-'Arabiyyah Mustawa Tsalits Ma'had Az-Zubair Bin AlAwwam," EL-TSAQAFAH Jurnal Jurusan PBA 19, no. 1 (2020): 25-36, https: journal.uinmataram.ac.id/index.php/eltsaqafah\%0AKORELASI. 
pembiasaan kecuali Ibu Martina yang terkadang memberi reward dan Ibu Nurmisyam memberikan sangsi.

Dari hasil observasi penulis dilapangan penulis menemukan bahwa tidak ada warga desa Pakasai dengan jenis kelamin perempuan dewasa yang tidak melaksanakan puasa, kecuali dalam keadaan halangan atau sebab lainnya. Namun berbeda dengan jenis kelamin laki-laki dewasa, secara terang- terangan berani berbuka di bulan ramadhan dengan alasan bekerja keras, namun ada juga yang tidak sedang bekerja tetap berbuka. Hal ini sangat disayangkan sekali. Jika dilihat dari masa kecil masing-masing yang berbuka tadi, mereka dahulunya adalah orang yang patuh, mampu menjalankkan puasa, namun pada saat ini mereka digoyahkan imannya dengan bekerja di bulan ramadhan sehingga menjadikan alasan bekerja untuk berbuka di bulan ramadhan itu.

Hasil observasi dan wawancara penulis tentang pengenalan dan pelaksanaan puasa, penulis menyimpulkan bahwa para keluarga terdekat sudah mengenalkan puasa semenjak dini dengan metode pembiasaan, walaupun baru setengah hari tapi dilakukan terus menerus akhirnya tidak ada anak yang membatalkan puasanya hingga saat ini, kecuali Yugo Ardi. Ada juga sebagian yang menambahkan metodenya dengan pemberian reward seperti Ibu Nurmisyam, Elvinawati, Kasmawati, Alianis, martina dan Masni.

Dari observasi penulis dilapangan praktek amal shaleh ini sudah terbiasa dilakukan di desa Pakasai, contoh shalat sunnah sering dilakukan jemaah di surau sewaktu baru datang atau selesai shalat wajib, shalat tarawih dan witir atau shalat Idul itri dan Idul Ahda. Begitu juga dengan puasa sunnah, para remaja dan ibu-ibu sering melakukan puasa Senin kamis, puasa muharam, puasa arafah, adapun kegiatan berzikir rutin dikerjakan sewaktu selesai shalat berjamaan di surau, dan bersedekah juga sering dilakukan oleh warga desa pakai seperti berbagi makanan, sedekah ke surau / badoncek, memberi sedekah pakiah, atau memberi bantuan tenaga dalam kegiatan sukka atau duka.

Dari observasi penulis dilapangan tingkat kerjasama dalam desa masih tinggi namun sudah berkurang dari tahun-tahun sebelumnya, salah satu contoh adalah dahulunya dalam membangun sebuah rumah baru, warga masyarakat satu desa menyediakan harinya untuk membantu dalam satu hari tersebut, namun sekkarang yang membantu hanya keluarga terdekat saja. Kemudian kegiatan gotong royong sudah jarang dilakukkan yang dahulunya sudah menjadi kegiatan wajib desa sekali 3 bulan. Disamping itu zaman penulis kecil jika ada yang meninggal maka warga secara sukarela menggali kubur si mayat, namun sekarang warga yang bekerja dicari dulu dan dibayar upah.

Adapun dari sikap menghargai orang lain, hal ini sudah agak berubah, karena dulunya anak-anak takut dengan paman atau teman-teman dari pamannya, namun saat ini itu sudah hilang dan menganggap hal biasa dalam bergaul, Kemudian nilai bertegur sapa juga berkurang, dulu walaupun tidak kenal, tapi tahu bahwa seseorang itu adalah warga desanya maka jika bertemu 
dia akan saling menyapa, namun saat ini jiwa untuk bertegur sapa sudah kurang, walaupun dia mengenal bahwa itu adalah warga sedesanya.

Kemudian dalam hal menyambung silaturrahmi, hal ini juga semakin berkurang, dulunya warga masyarakat saling bantu membantu dalam hal suka dan duka, namun saat ini jika ada yang meninggal yang datang hanya mewakili 1 atau 2 orang dari satu rumah. Dahulunya kalau ada kematian maka orang tua dan ana-anaknya yang sudah remaja dan dewasa semuanya ikut melayat, bahkan terkadang membawa anak kecil. Dari hasil Observasi dan wawancara penulis di atas, penulis menyimpulkan bahwa metode yang digunakan dalam penanaman nilai-nilai sosial kemasyarakatan adalah metode keteladanan dan pembiasaan, keteladanan contohnya Ibu Jamini sering menegur orang yang lewat, atau pembiasaan seperti Ibu Nurmisyam yang mengajak cucunya membantu di acara pesta atau kematian.

Tuliskan sesuai dengan rumusan masalah yang ditulis pada bagian Pendahuluan. Misal: Kegiatan pengabdian masyarakat yang dilaksanakan oleh mahasiswa/i STAI As-sunnah di desa....untuk mengatasi.....diantaranya pembelajaran al-quran untuk anak-anak, kegiatan ini melibatkan....dst.; Adapun dampak dari kegiatan-kegiatan tersebut cukup positif, terlihat dari antusisme masyarakat dalam mengikutinya..dst. Semuanya ditulis dalam bentuk deskriptif saja tanpa penomoran-penomoran/sub judul, dan lengkapi dengan data yang memadai. Hasil-hasil analisis tersebut harus bisa menjawab rumusan masalah di bagian pendahuluan.

\section{Penutup}

Dari hasil penelitian penulis di Desa Pakasai tentang Metode Penanaman nilai-nilai pendidikan Islam oleh keluarga terdekat terhadap Anak Korban Perceraian maka penulis menyimpulan sebagai berikut Pertama, Metode Penanaman nilai-nilai aqidah yaitu dengan membacakan kalimat tauhid sewaktu baru lahir yaitu melalui azan dan iqamah, dan mengajarkan kembali ketika anak pada usia balita dan kanak-kanak dengan metode pembiasaan, metode pembiasaan ini berbeda-beda antara keluarga yang mendidik, seperti dengan pembiasaan zikir, pelafalan sehari-hari, atau melalui nyanyian. Kedua Metode penanaman nilai-nilai ibadah yang diterapkan keluarga terdekat dalam hal mengerjakan shalat adalah dengan metode pembiasaan, dimulai dengan mengajak untuk ikut shalat bersama, membiasakan membacakan ayat pendek dan bacaan shalat menjelang tidur serta memberikan reward bagi anak yang mampu mengerjakannya. Disamping itu ada juga yang menggabungkkan dengan metode kisah. Namun masih ada keluarga terdekat yang tidak mampu untuk mengajari anak tersebut sehingga anak diserahkan ke surau atau sekolah. Ketiga, Metode penanaman nilai-nilai akhlak baik dalam hal akhlak terhadap Allah, terhadap diri sendiri dan akhlak terhadap manusia dan makhluk lainnya adalah dengan metode keteladanan seperti menampiklan akhlak yang baik dalam kehidupan sehari-hari, pembiasaan dengan berakhlakul karimah , memberikan 
nasehat- nasehat dan hukuman jika melakukan kesalahan. Disamping itu juga metode cerita atau penelaahan peristiwa.

\section{Bibliografi}

Al-kusyairi, M Khoir. "Nilai-Nilai Pendidikan Dalam Hadits Ibadah Aqiqah." Jurnal Al-Hikmah 12, no. 47 (2015). https://journal.uir.ac.id/index.php/alhikmah/article/view/1456.

Alim, Nur, Mahyudin Ritonga, and Mafardi. "Korelasi Kegiatan Ekstrakurikuler Sanggar Al-Quran Dengan Hasil Belajar Al-Quran Hadits Di MAN 4 Pasaman Barat." Intiqa: Jurnal Agama Dan Pendidikan Islam 12, no. 2 (2020). https://doi.org/10.30596/intiqad.v12i2.4640.

Azhar, Ahmad Lahmi, Aguswan Rasyid, Mahyudin Ritonga, and Riki Saputra. "The Role of Parents in Forming Morality Adolescents Puberty in Globalization Era." International Journal of Future Generation Communication and Networking 13, no. 4 (2020).

Azizah, Nurul. "Nilai-Nilai Pendidikan Islam Dalam Hadis-Hadis Akikah." PROGRESS: Jurnal Pendidikan Agama Islam Universitas Wahid Hasyim 7, no. 1 (2019).

Bambang, Mahyudin Ritonga, and Ahmad Lahmi. "The Role of Parents in Shaping Children's Behavior During the Covid-19 Pandemic." International Journal of Disaster Recovery and Business Continuity 11, no. 3 (2020).

Budiyanto, Tenda. "Membangun Komitmen Dalam Pernikahan Dan Keluarga." Tsamrah Al-Fikri 12, no. 2 (2018).

Dewi, Kartika Sari, and Adriana Soekandar. "Kesejahteraan Anak Dan Remaja Pada Keluarga Bercerai Di Indonesia: Reviu Naratif Kartika.” Wacana 11, no. 1 (2019). https://doi.org/10.13057/wacana.v11i1.135.

Fauziah, Reni, Mahyudin Ritonga, and Fitri Alrasi. "Korelasi Tsiqah Tahfidz AlQur'an Dengan Maharah Al-Lughah Al-'Arabiyyah Mustawa Tsalits Ma'had Az-Zubair Bin Al-Awwam." EL-TSAQAFAH Jurnal Jurusan PBA 19, no. https:journal.uinmataram.ac.id/index.php/eltsaqafah\%0AKORELASI.

Fincham, Frank D, and Steven R H Beach. "Conflict in Marriage: Implications for Working with Couples.” Annu. Rev. Psychol. 50, no. February (1999). https://doi.org/10.1146/annurev.psych.50.1.47.

Hakim, Rosniati, Mahyudin Ritonga, Khadijah, and Wetti Susanti. "Implementation of Contextual Teaching and Learning in Islamic Education at Madrasah Diniyah." Journal of Advanced Research in Dynamical \&. Control Systems 12, no. 02 (2020): 3326-32. https://doi.org/10.5373/JARDCS/V12I2/S20201455.

Hidayat, Nurul. "Metode Keteladanan Dalam Pendidikan Islam." Ta'allum: Jurnal Pendidikan Islam 03, no. 02 (2015). https://doi.org/10.21274/taalum.2015.3.2.135-150. 
Husein, Saddam, Radiudin Alfian Sangadji, and Laganti Salayar. "Urgensi Mempelajari Al-Qur'an Hadist Terhadap Prestasi Belajar Peserta Didik Di MTs Nurul Ikhlas Kalapa Dua Seram Bagian Barat.” Al-Iltizam 3, no. 1 (2018).

Irani, Luthfita Cahya, and Eko Pramudya Laksana. "Konsep Diri Dan Keterbukaan Diri Remaja Broken Home Yang Diasuh Nenek." Jurnal Pendidikan: Teori, Penelitian, Dan Pengembangan 3, no. 5 (2018).

Mone, Harry Ferdinand. "Dampak Perceraian Orang Tua Terhadap Perkembangan Psikososial Dan Prestasi Belajar." Harmoni Sosial: Jurnal Pendidikan IPS 6, no. 2019 ). https://doi.org/10.21831/hsjpi.v6i2.20873.

Multahada, Asyruni. "Keterampilan Menggunakan Metode Cerita Dalam Pembelajaran Pendidikan Agama Islam Di TPQ." Intizar 24, no. 2 (2018). https://doi.org/10.19109/intizar.v24i2.2586.

Ndayambaje, E, Y Umwari, and Y. Ayriza. "The Impact of Family Conflicts on Children's Education." International Journal of Pedagogy and Teacher Education 4, no. 2 (2020).

Nurlaili, Mahyudin Ritonga, and Mursal. 'Muroja'ah Sebagai Metode Menghafal Al-Qur'an Studi Pada Rumah Tahfiz Yayasan Ar-Rahmah Nanggalo Padang." Menara Ilmu XIV, no. 02 (2020).

Roskos, P. Tyler, Paul J. Handal, and Megan E. Ubinger. "Family Conflict Resolution: Its Measurement and Relationship with Family Conflict and Psychological Adjustment." Psychology 1, no. 5 (2010). https://doi.org/10.4236/psych.2010.15046. 